\title{
Magnetic field as a method of improving the quality of sowing material: a review
}

\author{
Stanisław Pietruszewski ${ }^{*}$ and Elvira Martínez ${ }^{2}$ \\ ${ }^{1}$ Departament of Physics, University of Life Science, Akademicka 13, 20-950 Lublin, Poland \\ ${ }^{2}$ Departament of Physics and Mechanics, College of Agricultural Engineering, Technical University, \\ Ciudad Universitaria s/n, 28040 Madrid, Spain
}

Received December 30, 2014; accepted May 11, 2015

\begin{abstract}
A b s t r a c t. The effect of magnetic field on the growth and yield of crop plants is presented based on 80 references on the studies of many authors. The introduction gives an outline of the history of the effect of magnetic field on biological organisms including plants since the second half of the 19th century. Then the role of static and alternating magnetic fields is discussed in relation to seed germination, root and stem growth, yield, protein and chlorophyll content, rhizosphere community.

$\mathrm{K}$ e y w o r d s: magnetic field, crop plants, magnetic presowing treatment
\end{abstract}

\section{INTRODUCTION}

At the start of the 21 st century science faces the serious challenge of ensuring sufficient supply of good and healthy food for the growing population of the Earth. To solve that problem, research is conducted at numerous research centres on the improvement of sowing material of crop plants. One of the many methods being tested is the application of magnetic or electromagnetic fields for that purpose.

The study of the effect of magnetic field on biological organisms, including plants, dates back to the second half of the 19th century. The first documented work in this regard is the publication from 1876 (Reinke, 1876) which presents the results of experiments concerned with the effect of magnetic field on plant development. Based on the presented data no effect of magnetic field on seed germination and plant growth was found. Similarly, no effect of magnetic field on seed germination was observed in the study by D'Astre (1882). Whereas, in a later publication (Tolomei, 1893) the effect of faster germination in magnetic field was documented. That was also the first study demonstrating the effect of magnetotropism. The phenomenon of magnetotropism, discovered by Tolomei, was subsequently studied more thoroughly by Audus (1960). It should also be added that in the years 1900-1901 a two-

*Corresponding author e-mail: s.pietruszewski@up.lublin.pl volume monograph was published (Danielewski, 1901), in which the author presented an extensive discussion of the experimental and theoretical foundations of the effect of electromagnetic field on various biological structures from cells to entire organisms.

The classic and historical works include also a publication from 1903 (Ewart, 1903). It reports that in aquatic plants (Valisneria and Chara) placed in magnetic field the movement of cytoplasm ceases if the lines of the magnetic field are perpendicular to the direction of the movement, while a parallel field does not produce that effect. That phenomenon was confirmed thirty years later by Sawostin (1930) who observed that in a parallel magnetic field with flux density of $7000 \mathrm{Oe}(0.7 \mathrm{~T})$ the movement of cytoplasm decreases by $15-30 \%$, while in perpendicular magnetic field with the same flux density the cytoplasm movement is accelerated. Sawostin observed also that magnetic field accelerates the growth of plant roots and increases the permeability of cell membrane. He succeeded in growing wheat sprouts that were $100 \%$ longer than average ones.

However, the development of biomagnetic studies took place only in the sixties and seventies of the 20th century. At that time, in the United States (Barnothy, 1964, 1969) and in the former USSR there appeared significant monographs concerning the effect of magnetic field on biological organisms (Presman, 1971; Cholodov, 1978).

The nineteen seventies were the time of numerous studies conducted in Canada. In a work published in 1970 (Pitman and Ormrod, 1970) it was demonstrated that wheat kernels subjected to the effect of magnetic field of $\mathrm{H}=1800$ Oe $(0.18 \mathrm{~T})$ had a different respiration coefficient than control seeds. Germinating seeds treated with the magnetic field had slower respiration, the difference being $20 \%$ after $20 \mathrm{~h}$ and getting smaller with further passage of time.

(C) 2015 Institute of Agrophysics, Polish Academy of Sciences 
Whereas, in a study by Pitman and Ormrod (1971) published a year later it was noted that seeds of brewing barley germinated earlier by from 8 to $12 \mathrm{~h}$ compared to control. Applying a magnetic field of $\mathrm{H}=1500 \mathrm{Oe}(0.15 \mathrm{~T})$, at temperature $\mathrm{t}=23^{\circ} \mathrm{C}(300 \mathrm{~K})$, and conducting experiments for $120 \mathrm{~h}$ (Pitman et al., 1979), it was found that amylolytic activity in germinating seeds can be caused by magnetic field treatment before soaking the seeds for germination. The appearance of starch encasing fragments of plant tissues indicated that we were dealing with the activity of $\alpha$-amylase and not $\beta$-amylase. The magnetic field distinctly inhibited the activity of that enzyme.

Experiments with seeds of wheat Kharkov 22MC (Pitman, 1967) demonstrated that a weak magnetic field $(100 \mathrm{Oe}-0.01 \mathrm{~T})$ causes germination accelerated by $8-12 \mathrm{~h}$ relative to seeds placed in a magnetic field equal to the geomagnetic field $(0.5 \mathrm{Oe}-0.05 \mathrm{mT})$. Moreover, kernels stored at temperature of $26^{\circ} \mathrm{C}(303 \mathrm{~K})$ grew faster than ones kept at $7^{\circ} \mathrm{C}(280 \mathrm{~K})$. The differences disappeared in magnetic field with flux density of 1500 Oe. The same author (Pitman, 1963, 1965) conducted field experiments at agricultural stations in the province of Alberta (Canada). During the four years of the experiments, pre-sowing stimulation was performed for seeds of five wheat cultivars, three barley cultivars, one oat cultivar. Depending of the magnet type used, the value of magnetic induction of static magnetic field varied from 50 to 650 Oe $(0.005-0.065 \mathrm{~T})$. The seeds were sown on identically prepared plots. The criterion in the estimation of the stimulation method applied was the yield obtained. In the case of oat no effect of magnetic field was noted. For the three wheat cultivars the responses were varied. Cultivars Nepava and Sundence showed a significant increase of yields in the first two years, but the third year did not confirm that trend. In the case of barley a distinct increase of yields was obtained, in the range of 2.8-6.5 q ha-1 and moreover the test plants matured earlier by 3-5 days and were taller by $5-8 \mathrm{~cm}$ compared to control. Whereas, there was a decrease in the bulk density of the seeds, by $0.96 \mathrm{~kg} \mathrm{dm}^{-3}$. Pitman related the results obtained to the duration of the time between the stimulation and sowing, and with the model of magnet used. That last conclusion appears to be a major methodological error, as it is not the model of magnet that determines the effects of magnetic stimulation, but the character of magnetic field that it generates. Moreover, as indeed he admits, yields are dependent on climate-environmental factors which are not fully researched. Chao and Walker (1967) used a horseshoe magnet with magnetic induction of $600 \mathrm{Gs}(0.06 \mathrm{~T})$ for presowing stimulation of seeds of apple, peach and apricot. Apple seeds subjected to the effect of the magnetic field germinated 5 days earlier than control seeds. Their germination lasted for 18 days and was shorter by a week than that of non-stimulated seeds. Also in the case of apricot seeds a positive effect of the magnetic field was observed. The germination was earlier by 3 days and lasted shorter.
In both cases the number of germinated seeds was greater than in the case of control seeds. In the case of peach seeds the magnetic field treated seeds did not germinate at all, and the number of germinated control seeds was negligible, so in that case it was hard to conclude what was the effect of pre-sowing magnetic field stimulation of the seeds on the process of germination.

In Poland the first studies on the effect of magnetic field on seeds were conducted by Kopeć $(1984,1985)$. They were concerned with the effect of magnetic field on cucumber seeds, but the results obtained were ambiguous. Both a positive effect and an absence of effects were found.

At present studies on the effect of magnetic field on the growth and yields of crop plants are conducted at numerous research centres all over the world.

In the case of pre-sowing stimulation of seeds it is important to identify a physical value which can serve for the determination of the effect of magnetic field on the process of germination and subsequently on the yields. Such a value is the magnetic exposure dose ie the product of the flux density of magnetic field and of the time of exposure.

The magnetic exposure dose is the product of the flux density of magnetic (electric) field and of the time of exposure. The flux density of an electric or magnetic field is defined by an equation obtained by integrating the equation describing electromagnetic field (Pietruszewski, 1999):

$$
\rho=\frac{1}{2} \varepsilon_{0} E^{2}=\frac{1}{2} \mu_{0} H^{2}=\frac{1}{2 \mu_{0}} B^{2},
$$

where: $\varepsilon_{0}$ - vacuum electric permittivity, $\mu_{0}$ - vacuum magnetic permittivity, $E$ - electric field intensity, $H$ - magnetic field intensity, $B$ - magnetic induction.

The flux density of magnetic field will be different when we are using a static magnetic field, and different when we use a variable (alternating) magnetic field. The intensity of magnetic fields is determined by means of teslameters. The teslameter determines the value of magnetic induction on the basis of measurement of Hall voltage which appears in the Hall effect sensor. In the case of variable magnetic induction we measure the effective value of that voltage, and thus also of the 'effective' value of magnetic induction. Taking into account that for harmonic frequencies $B=B_{e} \sqrt{2}$ or $B=B_{p} \sqrt{2}$, where $B_{p}$ is the value measured by the teslameter, in the case of a static magnetic field the flux density is:

$$
\rho_{s}=\frac{1}{2 \mu_{0}} B^{2},
$$

and for a variable (alternating) magnetic field:

$$
\rho_{a}=\frac{1}{\mu_{0}} B^{2},
$$


where: $B$ - value of magnetic induction measured with teslameter (in teslas).

Knowing that $\mu_{0}=\frac{10^{-7}}{4 \Pi}$ we obtain:

$$
\rho_{s}=\frac{10^{7}}{8 \Pi} B^{2}, \quad \text { and } \quad \mu_{a}=\frac{10^{7}}{4 \Pi} B^{2},
$$

The exposure dose $(D)$ is then defined by the relation:

$$
D=\rho t
$$

where: $\rho$ - flux density of magnetic field, $t-$ time of exposure.

The effect of magnetic field on seeds can be determined through the study of germination kinetics after prior magnetic field stimulation of the seeds. In this case, the germination kinetics curves obtained are described by one of the logistic curves which represents that effect the best.

On the basis of experimental data, we can fit eg the curvilinear equation of Malthus-Verhulst (Pietruszewski, 2001):

$$
N(t)=\frac{N_{k}}{1+\left(N_{k}-1\right) \exp \left[\alpha N_{k}\left(t-t_{0}\right)\right]},
$$

where: $N(t)$ - number of germinated kernels in time t, $N_{k}$ - final number of germinated kernels, $\alpha$ - germination speed coefficient, $t_{0}$ - time of germination of the first kernel.

On the basis of the logistic curve also the speed of germination was determined:

$$
v_{k}=\frac{d N(t)}{d t}=N(t) \cdot \alpha \cdot\left[N_{k}-N(t)\right],
$$

where: $v_{k}$-germination speed.

Both the logistic curve and the germination speed curve model the process of germination of stimulated seeds very well, and the fitting errors of the curves do not exceed $8 \%$. Differentiating Eq. (7) and comparing it to zero we get the possibility of determining the extreme value (maximum) of germination speed and the time at which it occurred:

$$
\frac{d^{2} N(t)}{d t^{2}}=\alpha \cdot N(t) \cdot\left[N_{k}-N(t)\right] \cdot\left[N_{k}-2 N(t)\right],
$$

and $t=t_{\max }$ for $N_{k}=2 N(t)$, and then we get:

$$
t_{\max }=\frac{\ln \left(N_{k}-1\right)}{\alpha \cdot N_{k}}+t_{\mathrm{o}} .
$$

It is also possible to use another logistic function (Dziewulska-Hunek and Kornarzyński, 2009; Kornarzyński and Pietruszewski, 2005; Torres and Frutos, 1990), such as:

$$
N(t)=N_{k}[1+\exp (\beta-K t)]^{-1},
$$

where: $N(t)$ - number of germinated seeds in time t, $N_{k}-$ final number of seeds, $B$ and $K$ - coefficients, $t$ - time of germination.

Experiments were conducted with the application of two exposure doses in pre-sowing magnetic field stimulation of spring wheat seeds. The experiments were concerned with measurements of germination kinetics that were subsequently verified in field experiments. After 4 days from the final stimulation, the seeds were sown on experimental plots at the rate of 600 kernels per $1 \mathrm{~m}^{2}$ in 5 replications including the control treatment. The harvest was made by hand (Pietruszewski and Kania, 2010).

The magnetic exposure doses were obtained in two ways (Table 1). Dose D13 was obtained over three consecutive days using alternating magnetic field with magnetic induction of $30 \mathrm{mT}$ and exposure time of $6 \mathrm{~s}$. The identical dose D11 was obtained at $45 \mathrm{mT}$ and exposure time of 8 seconds. Dose D23 was obtained applying a field of $30 \mathrm{mT}$ and exposure time of 8 seconds for three consecutive days, and dose D13 in a single treatment at magnetic induction of $60 \mathrm{mT}$ and exposure time of $8 \mathrm{~s}$.

T a b l e 1. Parameters of the magnetic exposure dose

\begin{tabular}{lcccc}
\hline & \multicolumn{3}{c}{ Day } & $\begin{array}{c}\text { Dose } \\
\text { value } \\
\left(\mathrm{kJ} \mathrm{m}^{-3} \mathrm{~s}^{-1}\right)\end{array}$ \\
\cline { 2 - 5 } Dose & 1 & 2 & 3 & 12.9 \\
D13 & $30 \mathrm{mT}, 6 \mathrm{~s}$ & $30 \mathrm{mT}, 6 \mathrm{~s}$ & $30 \mathrm{mT}, 6 \mathrm{~s}$ & 12.9 \\
D21 & & & $60 \mathrm{mT}, 8 \mathrm{~s}$ & 17.2 \\
D23 & $30 \mathrm{mT}, 8 \mathrm{~s}$ & $30 \mathrm{mT}, 8 \mathrm{~s}$ & $30 \mathrm{mT}, 8 \mathrm{~s}$ & 17.2 \\
\hline
\end{tabular}

The germination kinetics of seeds subjected to pre-sowing stimulation with magnetic field was described with the Malthus-Verhulst Eq. (6).

The germination kinetics for all the exposure doses and for the control treatment were recorded in three replicates by means of an electronic seed germinator (Patent, PL 378397). Germination kinetics curves were plotted on the basis of the calculated mean values. Then, for the particular germination kinetics curves, logistic curves were fitted in accordance with Eq. (6) and the parameters of the logistic curves were calculated, the values of which are given in Table 2.

The results of the field tests, taking into account their statistical evaluation, are presented in Table 3. The field experiments support the results obtained earlier by means of the electronic seed germinator. The level of yields and the biometric features of the plants are dependent on the value of the magnetic exposure dose, irrespective of the manner of its obtainment. Magnetic field does not act selectively, but has an overall effect. Not only the yields for seeds subjected to pre-sowing stimulation are higher, 
T a b l e 2. Parameters of the logistic curve

\begin{tabular}{lccccc}
\hline Dose & $N_{k}(\%)$ & $t_{0}(\mathrm{~h})$ & $\alpha(1 / \% \mathrm{~h})$ & $t_{\max }(\mathrm{h})$ & $V_{k \max }(\% / \mathrm{h})$ \\
\hline $\mathrm{C}$ & 94 & 16 & 0.005 & $25.35 \pm 1.17$ & $10.9 \pm 0.9$ \\
D11 & 96 & 17 & 0.008 & $23.22 \pm 1.16$ & $17.5 \pm 0.8$ \\
D13 & 93 & 17 & 0.008 & $23.36 \pm 1.16$ & $16.5 \pm 0.8$ \\
D21 & 96 & 16 & 0.007 & $22.70 \pm 1.14$ & $13.6 \pm .07$ \\
D23 & 97 & 15 & 0.006 & $23.01 \pm 1.15$ & $13.7 \pm 0.7$ \\
\hline
\end{tabular}

T a b l e 3. Effect of the pre-sowing exposure dose on yield parameters after statistical evaluation

\begin{tabular}{|c|c|c|c|c|c|c|}
\hline \multirow{2}{*}{ Parameter } & \multicolumn{5}{|c|}{ Exposure dose } & \multirow{2}{*}{ LSD } \\
\hline & Control & D11 & D13 & D21 & D23 & \\
\hline Spike length (cm) & $5.72 \mathrm{a}$ & $6.74 b$ & $6.78 \mathrm{~b}$ & $7.32 \mathrm{c}$ & 6.66 & 0.87 \\
\hline Number of spikes $\left(\mathrm{m}^{2}\right)$ & $505 \mathrm{a}$ & $522 b$ & $526 \mathrm{~b}$ & $536 b$ & $537 \mathrm{~b}$ & 13.7 \\
\hline Yield $\left(\mathrm{m}^{2}\right)$ & $369 a$ & $448 b$ & $476 b$ & $514 \mathrm{c}$ & $557 \mathrm{c}$ & 38.3 \\
\hline Culm height $(\mathrm{cm})$ & $70 \mathrm{a}$ & $82 b$ & $85 b$ & $86 b$ & $83 b$ & 3.7 \\
\hline
\end{tabular}

Means in the same row with the same letters are not significantly different.

relative to the control, but the stems of the plants are higher as well. That last trait is undesirable, as it may lead to the lodging of cereal plants.

A static magnetic field was applied for pre-sowing stimulation of seeds of cabbage and onion (Pietruszewski, 2002). Cabbage seeds were stimulated with magnetic fields with induction values of 70,120 and $210 \mathrm{mT}$, while onion seeds with fields of 40 and $80 \mathrm{mT}$. The germination results obtained permitted the plotting of logistic curves on the basis of Eq. (6). The logistic curves are presented in Fig. 1. The black dots represent values obtained from measurements, while the lines are the logistic functions calculated. Cabbage seeds germinated at the same rate irrespective of the value of magnetic induction applied for the pre-sowing stimulation. Onion seeds responded differently to the stimulation. Earlier germination was noted for seed stimulated with the magnetic field of $80 \mathrm{mT}$. Apart from that, the logistic curves could not be fitted as perfectly as in the case of cabbage seeds. The results obtained demonstrate that the effect of magnetic field depends not only on the value of magnetic induction applied, but also on the kind of seeds (plants) subjected to the stimulation.

To determine the effect of a static magnetic field a study was conducted on the relative germination capacity of wheat kernels (germination capacity of stimulated seeds/ germination capacity of control seeds) for various values of magnetic induction.

The results obtained are presented in Fig. 2. Observations were conducted after 30, 35, 40, 45 and $50 \mathrm{~h}$ from stimulation (Pietruszewski et al., 2001b).

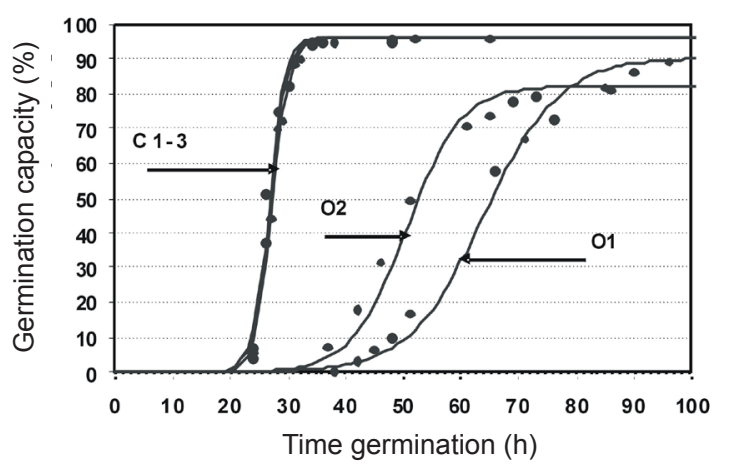

Fig. 1. Logistic curves for: cabbage C 1-3, onion O1 - 40, $\mathrm{O} 2-80 \mathrm{mT}$.

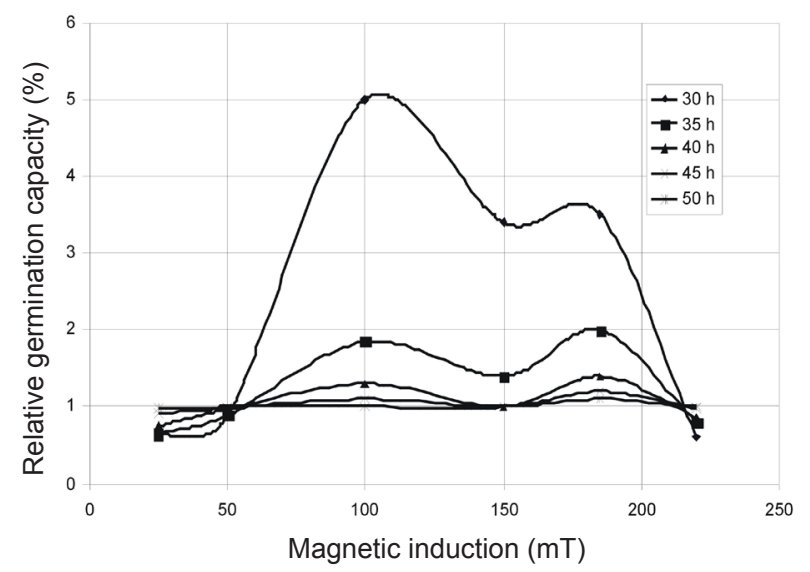

Fig. 2. Relative germination capacity of wheat kernels subjected to pre-sowing stimulation with static magnetic field. 
The best germination capacity was obtained for 100 and $180 \mathrm{mT}$.

A very weak static magnetic field of $0.5 \mathrm{mT}$ was applied for pre-sowing stimulation of onion seeds. An increase was obtained in leaf area and in the content of protein and chlorophylls in onion seedlings (Nowicki et al., 2001). Treatment of maize seeds with a static magnetic field of $150 \mathrm{mT}$ (Aladjadjiyan, 2007) resulted in stem growth in growing plants, and in the case of fields of $60-200 \mathrm{mT}-$ an increase of yields. The effect of a static magnetic field of $150 \mathrm{mT}$ at four exposure times (Aladjadjiyan, 2010) on the process of germination of lentil seeds demonstrated better germination of the seeds. Studies conducted in Spain were focused on seeds of rice and barley. The application of fields of 150 and $200 \mathrm{mT}$ resulted in faster germination of rice seeds (Carbonell et al., 2000), and in the case of a field of $125 \mathrm{mT}$ improved yields of barley were obtained at exposure time of $24 \mathrm{~h}$ (Martinez et al., 2000). Magnetic fields of 125 and $250 \mathrm{mT}$ produced by means of permanent magnets were used to study the effect of fields generated thereby on the germination of potato seeds (Martinez et al., 2009). A positive effect was observed for the exposure times applied, and curves of germination kinetics were plotted. It is a pity that the authors did not describe those curves with logistic equations. A static magnetic field of 2.9-4.6 mT was applied on soybean seeds (Atak et al., 2005). The magnetic field had a positive effect on root development and on the content of chlorophylls a and b. Static magnetic fields with various values of magnetic induction - 50, 100, 150, 200 and $250 \mathrm{mT}$ - were applied for pre-sowing stimulation of seeds of chickpea (Vashisth and Nagarajan, 2008). The positive effects observed concerned not only germination but also the length of roots and leaves. A static magnetic field of $250 \mathrm{mT}$ was applied to determine its effect on the germination and on seedling growth of sunflower (Vashisth and Nagarajan, 2010). It was found that the pre-sowing stimulation with the magnetic field caused not only faster germination but also an increase of seedling mass.

A combination of four different static magnetic fields, of $60,116,168$ and $200 \mathrm{mT}$, was applied to determine the germination of black gram (Vigna mungo) seeds (Mahajan and Pandey, 2011). A positive effect of the magnetic fields applied was observed, and in addition the germination kinetics was described with the use of the Malthus-Verhulst logistic equation. The combination of magnetic stimulation and magnetic-treated water was applied in relation to tomato seeds (Abou El-Yozied et al., 2012). Unfortunately, the authors used old units. The stimulation was performed using a magnetic field of $100 \mathrm{Gs}(10 \mathrm{mT})$, and the water was treated with a field of $800 \mathrm{Gs}(80 \mathrm{mT})$. The pre-sowing magnetic stimulation caused not only faster germination, but also better quality of yields. The combination of presowing magnetic stimulation and irrigation with magnetictreated water caused the same effect, but amplified. Another type of research is presented in a paper by Hirota

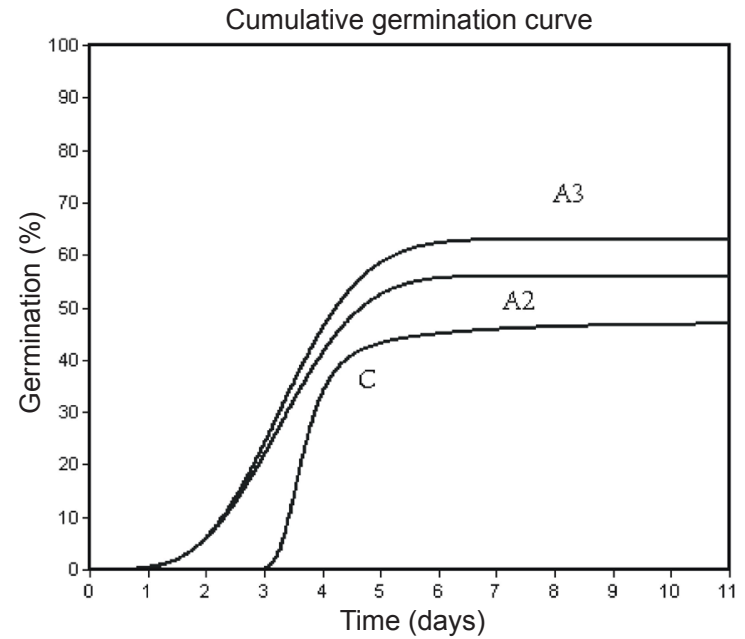

Fig. 3. Germination kinetics of common sage seeds at doses A2-20 min and A3-1h, and C-control (Flórez et al., 2012).

et al. (1999) who applied a static magnetic field of very high magnetic induction, in this case $10 \mathrm{~T}$. Such a strong magnetic field was obtained through the use of the phenomenon of superconductivity. In fields of 10 and $7 \mathrm{~T}$ vastly improved germination of cucumber seeds was observed relative to the control sample.

Seeds of common sage and marigold were treated with a static magnetic field of $125 \mathrm{mT}$ (Flórez et al., 2012). The germination of the seeds of the selected herbs was determined in relation to the exposure dose applied. The results were presented, among others, in the form of germination kinetics curves (Fig. 3). The results obtained are highly interesting.

Seeds of chickpea are a good object of research. Magnetic field of 20, 40, 60, 80 and $100 \mathrm{mT}$, obtained within a solenoid, was used for $1 \mathrm{~h}$ pre-sowing stimulation of seeds of two chickpea cultivars - Pusa 256 and Pusa 1055 (Simi et al., 2013). The length of roots and leaves was measured in relation to the direction of growth and to the direction of the magnetic field. The best effects were obtained when both of those directions coincided. The greatest increase of root length in cultivar 256 was noted for $60 \mathrm{mT}$, and in cultivar 1055 for $80 \mathrm{mT}$. The best increase in leaf length relative to the control sample was observed for cultivar 256 at $60 \mathrm{mT}$, and for cultivar 1055 at $100 \mathrm{mT}$.

The germination of black gram seeds in static magnetic field of 87, 157, 194 and $226 \mathrm{mT}$ (Mahajan and Pandey, 2014) was studied at exposure time of $100 \mathrm{~min}$. In all cases a positive effect of the magnetic field was observed. According to those authors, the germination kinetics is described well by the Malthus-Verhulst equation. They introduced a new concept - the 'magnetic-time model' ie the product of magnetic induction and of the time of exposure. The authors of this work conclude that the expression describes well the process of germination of seeds subjected to pre-sowing stimulation with magnetic field. 
T a b l e 4. Effect of static magnetic field on plants

\begin{tabular}{|c|c|c|c|}
\hline Name & Magnetic induction & Effect & References \\
\hline Common wheat & $20-215 \mathrm{mT}$ & Accelerated growth & Sawostin (1930) \\
\hline Algae & $20-215 \mathrm{mT}$ & $\begin{array}{l}\text { Stimulation or inhibition of } \\
\text { cytoplasm movement }\end{array}$ & Sawostin (1930) \\
\hline $\begin{array}{l}\text { Pea } \\
\text { Apricot } \\
\text { Apple }\end{array}$ & $60 \mathrm{mT}$ & Accelerated germination & Chao and Walker (1967) \\
\hline $\begin{array}{l}\text { Wheat } \\
\text { Kharkov 22MC }\end{array}$ & $10 \mathrm{mT}$ & Faster germination & Pittman (1967) \\
\hline Wheat & $180 \mathrm{mT}$ & $\begin{array}{l}\text { Different seed respiration } \\
\text { coefficient }\end{array}$ & Pitman and Ormrod (1970) \\
\hline Malting barley & $180 \mathrm{mT}$ & Faster germination & Pitman and Ormrod (1971) \\
\hline \multicolumn{4}{|l|}{ Ormrod } \\
\hline $\begin{array}{l}\text { Wheat } \\
\text { Barley }\end{array}$ & $150 \mathrm{mT}$ & $\begin{array}{l}\text { Faster germination, increase of } \\
\alpha \text {-amylase activity }\end{array}$ & Pitman et al. (1979) \\
\hline Beet PN Mono 3 & $1.26-25.2 \mathrm{mT}$ & Ambiguous results & Kopeć $(1984,1985)$ \\
\hline Cucumber & 7 and $10 \mathrm{~T}$ & Better germination & Hirota et al. (1999) \\
\hline Rice & 150 and $200 \mathrm{mT}$ & Better germination & 2000 Carbonell et al. \\
\hline Barley & $125 \mathrm{mT}$ & Better germination & Martinez et al. (2000) \\
\hline Onion & $5 \mathrm{mT}$ & $\begin{array}{l}\text { Increased leaf area and protein and } \\
\text { chlorophyll content }\end{array}$ & Nowicki et al. (2001) \\
\hline Wheat & $30-220 \mathrm{mT}$ & Better germination & Pietruszewski et al. (2001) \\
\hline White cabbage and onion & $40,70,80,120$ and $210 \mathrm{mT}$ & Better germination & Pietruszewski (2002) \\
\hline Soybean & $2.9-4.6 \mathrm{mT}$ & $\begin{array}{l}\text { Root growth and increased content } \\
\text { of chlorophylls a and } b\end{array}$ & Atak et al. (2005) \\
\hline Maize & $150 \mathrm{mT}$ & $\begin{array}{l}\text { Stem growth and increased } \\
\text { germination vigour }\end{array}$ & Aladjadijyan (2007) \\
\hline Chickpea & $50,100,150,200,250 \mathrm{mT}$ & $\begin{array}{l}\text { Increased germination, leaf and } \\
\text { root length }\end{array}$ & $\begin{array}{l}\text { Vashisth and Nagarajan } \\
\text { (2008) }\end{array}$ \\
\hline Tomato & 125 and $250 \mathrm{mT}$ & Better germination & Martinez et al. (2009) \\
\hline Lentil & $150 \mathrm{mT}$ & Better germination & 2010 Aladjadijyan \\
\hline Sunflower & $250 \mathrm{mT}$ & Better germination and yields & $\begin{array}{l}\text { Vashisth and Nagarajan } \\
\text { (2010) }\end{array}$ \\
\hline Black gram & $60,16,168,200 \mathrm{mT}$ & Better germination & Mahajan and Pandey (2011) \\
\hline Tomato & $\begin{array}{l}10 \mathrm{mT} \text { and magnetically } \\
\text { treated water }\end{array}$ & Better germination and yields & Abou El Yozied et al. (2011) \\
\hline Common sage and marigold & $125 \mathrm{mT}$ & Better germination & Florez et al. (2012) \\
\hline Chichpea & $20-200 \mathrm{mT}$ & Increased root length & Simi et al. (2013) \\
\hline Black gram & $87-226 \mathrm{mT}$ & Better germination & Mahajan and Pandey (2014) \\
\hline
\end{tabular}


Table 4 compiles all the references cited, listing the authors, year of publication, plants (seeds) studied, magnetic field used, and effects obtained.

The effects of static and alternating magnetic field on seeds differ, due to the character of the field. To determine the effect of alternating magnetic field a study was conducted on the relative germination capacity of wheat kernels (germination capacity of stimulated seeds/germination capacity of control seeds) for various values of magnetic induction.

The results obtained are presented in Fig. 4. Observations were conducted after 45, 48, 50, 53, 56 and $60 \mathrm{~h}$ from stimulation (Pietruszewski et al., 2001a).

The speed of germination of those kernels was determined on the basis of Eq. (7). Germination speed of seeds stimulated with alternating magnetic field was calculated for two values of magnetic induction used for the stimulation: 35 and $50 \mathrm{mT}$. Those were the fields for which the highest values of relative germination capacity were obtained. The procedure was the same as in the case of static magnetic field. In this case the calculations were made for 100 and $185 \mathrm{mT}$. The results obtained are presented in graphs (Fig. 5).

The presented results show that alternating magnetic field causes an increase of germination capacity relative to the control at lower values of magnetic induction than the static field (alternating field - $35 \mathrm{mT}$, static field - 100 and $185 \mathrm{mT}$ ). Also the speed of germination of whet ker- nels stimulated with the alternating magnetic field attains a higher maximum value than those stimulated with the static field, and $10 \mathrm{~h}$ sooner.

Alternating magnetic field is used both for the determination of its effect on seed germination and in pre-sowing stimulation verified in field experiments.

A field study with seeds of four beet cultivars - Colobri, Evita, Kawetina and Maria - was conducted in three successive years of vegetation (Pietruszewski and Wójcik, 2000). The value of magnetic induction applied for pre-sowing seed stimulation was $75 \mathrm{mT}$, and the times of exposure were $8,15,30$ and $60 \mathrm{~s}$, which corresponded to magnetic exposure doses of $35.84,67.2,134.4$ and $268.8 \mathrm{~kJ} \mathrm{~m}^{-3} \mathrm{~s}$. The results obtained showed that the magnetic field had a positive effect only in the case of cultivar Maria.

An alternating magnetic field was applied, at two exposure doses, D1 $=10.75 \mathrm{~kJ} \mathrm{~m}^{-3} \mathrm{~s}(30 \mathrm{mT}, 15 \mathrm{~s})$ and $\mathrm{D} 2=$ $85.99 \mathrm{~kJ} \mathrm{~m}^{-3} \mathrm{~s}(85 \mathrm{mT}, 15 \mathrm{~s})$, for pre-sowing stimulation of seeds of leguminous plants. In the first case the effect of the field was applied on seeds of broad bean (Podleśny et al., 2004), and in the second on seeds of pea (Podleśny et al., 2005), and the germination of the seeds and the plant yields were estimated. In the case of broad bean, better germination relative to control was observed, and higher yields. In the second case also improved germination was noted, and based on field tests it was found that better yields were obtained, especially in the case of cultivar Piast.

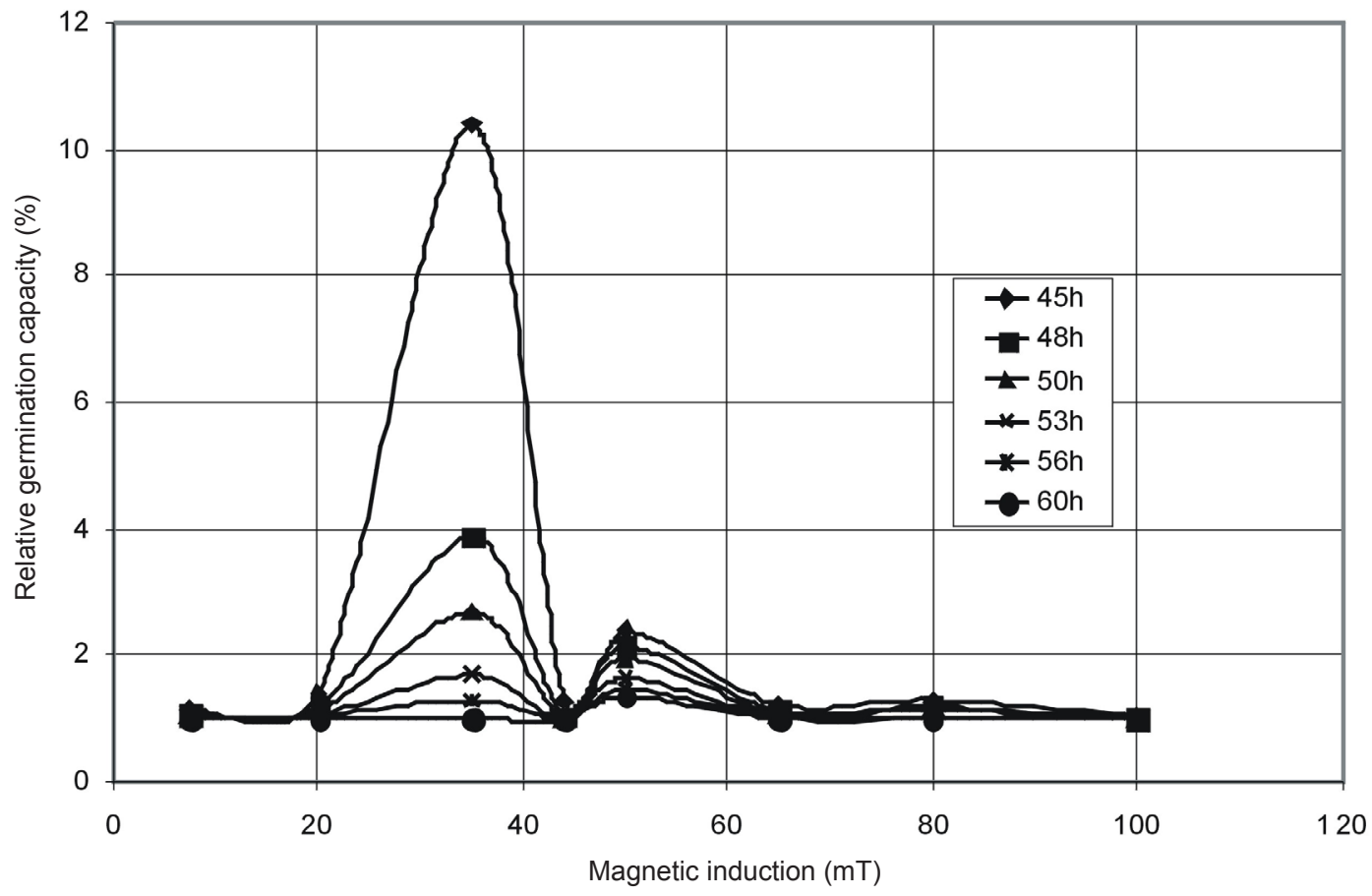

Fig. 4. Relative germination capacity of wheat kernels subjected to pre-sowing stimulation with alternating magnetic field. 


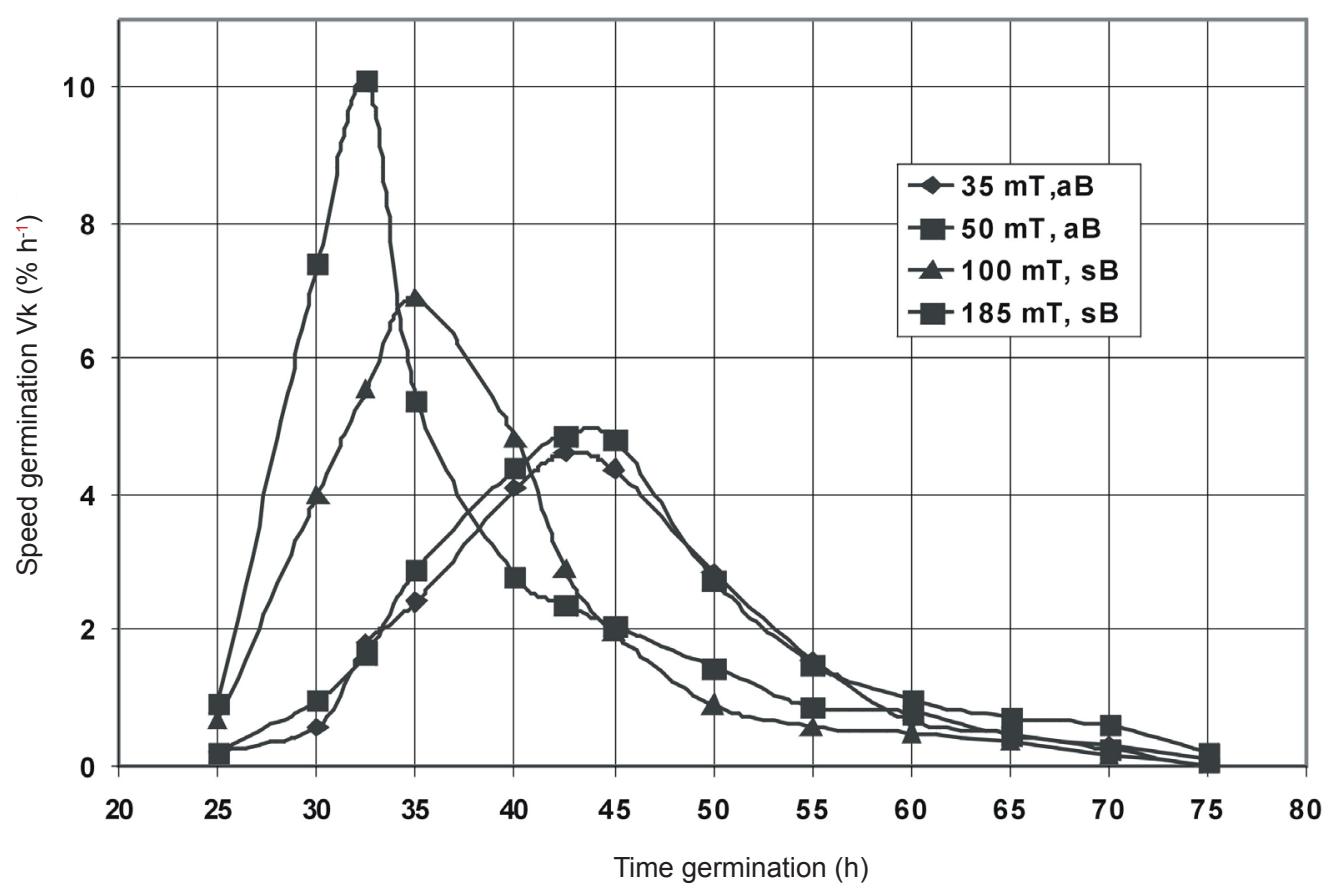

Fig. 5. Germination speed of wheat kernels stimulated with alternating and static magnetic field. aB - alternating and $\mathrm{sB}$ - static magnetic field.

A magnetic field with induction in the range of 40$78 \mu \mathrm{T}$ and frequency of $60 \mathrm{~Hz}$ was used to determine its effect on the germination of seeds of several plant species (Davis, 1996). The author of that study demonstrated that in the case of seeds of barley and radish the effect of magnetic field was positive and increased their germination capacity, root and leaf mass, and stem diameter. In the case of mustard, however, no effect was observed. Alternating magnetic induction of $15 \mu \mathrm{T}$ and $50 \mathrm{~Hz}$ was applied to determine its effect on the germination of seeds of cork oak (Celestino et al., 1998). The results presented by the authors demonstrate that such a weak magnetic field considerably improves the germination of the seeds.

Using a magnetic field with induction of $100 \mu \mathrm{T}$ and frequency of $50 \mathrm{~Hz}$ for pre-sowing stimulation of garden cress an acceleration of growth and an increase of green matter were observed (Guttzeit, 2001).

Rochalska et al. (2007) demonstrated that an alternating magnetic field of $16 \mathrm{~Hz}, 5 \mathrm{mT}$, caused an inhibition of alpha- and beta-amylase activity in the case of wheat. Whereas, in a study by Aksenov et al. (2001) it was demonstrated that a magnetic field of $50 \mathrm{~Hz}, 30 \mathrm{mT}$, applied on wheat stimulated the growth of roots and sprouts. A weak magnetic field of $20 \mu \mathrm{T}$ and frequency of $16^{2} / 3 \mathrm{~Hz}$ caused an increase of mass and plant height in the case of sunflower, while better germination of wheat was demonstrated in another study (Fischer et al., 2004). Ratushnyak et al . (2008) demonstrated that a high-frequency magnetic field of 30-60 GHz and flux of $10^{-16}-10^{-10} \mathrm{~W} \mathrm{~cm}^{-2}$, and exposure times of 5-15 min, caused a stimulation of microflora growth in the case of pine seeds.

A combination of alternating magnetic field and laser light was applied for the determination of the effect of both of those factors on seeds of amaranth (Sujak et al., 2009; Sujak and Dziewulska-Hunek, 2010). Seed stimulation with both factors and their combination produced an effect on the yields and on the content of microelements in the grain obtained.

The effect of alternating magnetic field $(60 \mathrm{~Hz})$ of 20,60 and $100 \mathrm{mT}$, for several times of exposure, on the emergence of three maize genotypes in field conditions is presented in a paper by Aguilar et al. (2009), concluding that the effect depends on the plant genotype. The effect of magnetic fields, in the range of $0.5 \mu \mathrm{T}$ to $30 \mathrm{mT}$ and long time of exposure, on the germination of a mixture of seeds of black medick and dodder (parasitic plant) is presented in another referenced paper (Balonchi et al., 2009). The magnetic fields applied improve the germination of black medick and inhibit that of dodder. The authors of that paper concluded that in the case considered the use of magnetic field treatment can be a weed control treatment. A positive effect of alternating magnetic field of $480 \mathrm{mT}$ and five exposure times was observed in the case of maize seeds (Zapeda Bautista et al., 2010). Whereas, pre-sowing stimulation with alternating magnetic field of $30 \mathrm{mT}$ did not cause any statistically significant increase of yields of spring wheat in the case of mechanised cultivation (Bujak and Frant, 2009). 
T a b l e 5. Effect of alternating magnetic field on plants

\begin{tabular}{|c|c|c|c|}
\hline Plant & Magnetic induction & Effect & References \\
\hline Barley, radish, mustard & $40-78 \mu \mathrm{T}, 60 \mathrm{~Hz}$ & $\begin{array}{l}\text { Positive effect on seeds of barley } \\
\text { and radish, no effect on mustard }\end{array}$ & Davis (1996) \\
\hline Cork oak & $15 \mu \mathrm{T}, 50 \mathrm{~Hz}$ & Better germination & Celestino et al. (1998) \\
\hline Sugar beet & $75 \mathrm{mT}, 50 \mathrm{~Hz}$ & Better yields for cv. Maria & $\begin{array}{l}\text { Pietruszewski and Wójcik } \\
(2000)\end{array}$ \\
\hline Wheat & $30 \mathrm{mT}, 50 \mathrm{~Hz}$ & Better germination & Aksenov et al. (2001) \\
\hline Garden cress & $100 \mu \mathrm{T}, 50 \mathrm{~Hz}$ & Seedling growth & Guttzeit (2001) \\
\hline Wheat & $10-100 \mathrm{mT}, 50 \mathrm{~Hz}$ & Effect on germination & Pietruszewski et al. (2001a) \\
\hline Pea & $30 \mathrm{mT}, 85 \mathrm{mT}, 50 \mathrm{~Hz}$ & Better germination and yields & Poleśny et al. (2004) \\
\hline Broad bean & $30 \mathrm{mT}, 85 \mathrm{mT}, 50 \mathrm{~Hz}$ & Better germination and yields & Poleśny et al. (2005) \\
\hline Sunflower & $20 \mu \mathrm{T}, 162 / 3 \mathrm{~Hz}$ & Better germination & Fischer et al. (2004) \\
\hline Pine & $30-60 \mathrm{GHz}$ & Growth of seed microflora & Ratushnyak et al. (2008) \\
\hline Maize & $20,60100 \mathrm{mT}, 60 \mathrm{~Hz}$ & Positive effect depending on cultivar & Aguilar et al. (2009) \\
\hline Dodder & $0.5 \mu \mathrm{T}-30 \mathrm{mT}$ & Growth inhibition & Balonchi et al. (2009) \\
\hline Amaranth & 30 mT 50 Hz. Laser He-Ne & Effect on yields & Sujak et al. (2009) \\
\hline Amaranth & 30 mT 50 Hz. Laser He-Ne & Effect on microelements & $\begin{array}{l}\text { Sujak and Dziwulska-Hunek } \\
\text { (2010) }\end{array}$ \\
\hline Wheat & $30 \mathrm{mT}, 50 \mathrm{~Hz}$ & No effect in field tests & Bujak and Frant (2010) \\
\hline Durum wheat & $15 \mathrm{mT}, 50 \mathrm{~Hz}$ & Better germination & Muszyński et al. (2009) \\
\hline Amaranth & $30 \mathrm{mT}, 50 \mathrm{~Hz}$ & Better germination & Dziwulska-Hunek et al. (2009) \\
\hline Maize & $480 \mathrm{mT}, 60 \mathrm{~Hz}$ & Better germination & Zepeda-Bautista et al. (2010) \\
\hline Potato & $20,40,80 \mathrm{mT}, 50 \mathrm{~Hz}$ & Better yields & Marks and Szecówka (2010) \\
\hline Wheat & $5 \mathrm{mT}, 16 \mathrm{~Hz}$ & Better emergence after 20 days & Rochalska et al. (2011) \\
\hline Sunflower & $30 \mathrm{mT}, 50 \mathrm{~Hz}$ & Better germination & Matwijczuk et al. (2012) \\
\hline Pea & $60,120,180 \mathrm{mT}, 50 \mathrm{~Hz}$ & $\begin{array}{l}\text { Better germination and increase of } \\
\text { chlorophylls } a \text { and } b\end{array}$ & Iqbal et al. (2012) \\
\hline Wheat, 5 cultivars & $30 \mathrm{mT}, 50 \mathrm{~Hz}$ & Better effects for $c v$. Banti & Pietruszewski et al. (2013) \\
\hline Hoary plantains & $350 \rightarrow 2000 \mathrm{mT}, 50 \mathrm{~Hz}$ & $\begin{array}{l}\text { Better germination and increase of } \\
\text { chlorophylls } a \text { and } b\end{array}$ & Shashurin et al. (2014) \\
\hline Radish & $500 \mu \mathrm{T}, 50 \mathrm{~Hz}$ & $\begin{array}{l}\text { Better germination and seedling } \\
\text { properties }\end{array}$ & Novitskii et al. (2014) \\
\hline Maize & $480 \mathrm{mT}, 60 \mathrm{~Hz}$ & Better yields & Zepeda-Bautista et al. (2014) \\
\hline Coffee $c v$. Arabica & $5 \mathrm{mT}, 60 \mathrm{~Hz}$ & Increase of chlorophylls $\mathrm{a}$ and $\mathrm{b}$ & Aleman et al. (2014) \\
\hline
\end{tabular}


The effect of magnetic field on the germination and growth of kernels of durum wheat (Triticum durum) is presented in a paper by Muszyński et al. (2009). Seeds of two amaranth cultivars, Aztek and Rawa, were subjected to pre-sowing stimulation with laser light, an alternating magnetic field of $30 \mathrm{mT}$, and the combination of laser + magnetic field (Dziewulska-Hunek et al., 2009). All of those treatments caused better germination of the seeds. Another combination of treatments was applied in the case of sunflower seeds (Matwijczuk et al., 2012). In this case an alternating magnetic field of $30 \mathrm{mT}$ and magnetically treated water were used. The results obtained were presented in the form of tables and logistic curves. They confirmed the positive effect of magnetic field and of the combination of magnetic field and magnetically treated water on the process of seed germination.

Three values of magnetic induction obtained by means of a specially designed solenoid supplied with alternating voltage of $50 \mathrm{~Hz}$ were applied for the determination of the effect of that field on potato yields and quality (Marks and Szecówka, 2010). The magnetic fields used were determined according to the exposure dose (Eq. 5). The best results were obtained for the highest dose of $18334.7 \mathrm{~kJ} \mathrm{~m}^{-3} \mathrm{~s}$ $(80 \mathrm{mT})$. In another study an alternating magnetic field of $16 \mathrm{~Hz}$ and $5 \mathrm{mT}$ was applied in relation to wheat (Rochalska et al., 2011). It was found that after 20 days from sowing a distinct positive effect of the pre-sowing stimulation with the magnetic field could be observed. An alternating magnetic field of $50 \mathrm{~Hz}$, magnetic induction of 60,120 and $180 \mathrm{mT}$ and exposure times of 5,10 and $15 \mathrm{~min}$ was applied in the case of pea seeds (Iqbal et al., 2012). The length of leaves and roots, the dry matter of leaves and roots and the content of chlorophylls $\mathrm{a}$ and $\mathrm{b}$ were analysed. The best effect on leaves and roots was noted for $120 \mathrm{mT}$ and $15 \mathrm{~min}$ and for $180 \mathrm{mT}$ and $10 \mathrm{~min}$. An increase of chlorophyll a was observed for $60 \mathrm{mT} 5$ and $15 \mathrm{~min}$ and for $120 \mathrm{mT}$ and $5 \mathrm{~min}$. Chlorophyll $\mathrm{b}$ increased in relation to the control for $60 \mathrm{mT}, 5 \mathrm{~min}$ and $120 \mathrm{mT}, 5 \mathrm{~min}$.

Pre-sowing stimulation of seeds of hoary plantain (Plantago media L.) is described in a paper by Shashurin et al. (2014) who used an alternating magnetic field of $50 \mathrm{~Hz}$ and magnetic induction values of $350,550,800$, 1150,1600 and $2000 \mathrm{mT}$. The authors determined the effect of the magnetic field on the germination and on the physiological and biochemical properties of seedlings. They found that the magnetic field did not affect seed germination. Chlorophyll $\mathrm{b}$ was the highest for magnetic field of $350 \mathrm{mT}$, while indices MDA, SOD and LMAO were notably higher than in the control for fields of 800 and $1150 \mathrm{mT}$.

Seeds of radish were treated with magnetic field of $50 \mathrm{~Hz}$ and $500 \mu \mathrm{T}$ generated by means of the Helmoholtz coil (Novitskij, 2014). A significant effect of the field on seed germination and on the biophysical properties of seedlings was observed.
Magnetic field of $480 \mathrm{mT}$ generated in a solenoid supplied with alternating voltage of $60 \mathrm{~Hz}$ was used to determine its effect on the yields of two maize cultivars: San Juan and San Jose (Zepeda-Bautista, 2014). Seeds were placed inside the coil for 3, 6, 9, 12 and 15 min. It was found that the plant height was the greatest for cultivar San Jose in relation to the control, for exposure time of $12 \mathrm{~min}$, while the yields of both cultivars were the highest for the same time of exposure.

Alternating magnetic field of $60 \mathrm{~Hz}$, magnetic induction of $2 \mathrm{mT}$ and exposure time of $3 \mathrm{~min}$ was applied for seeds of coffee cultivar Arabica (Aleman et al., 2014). After pre-sowing stimulation the seeds were sown and an increase of chlorophylls a and b relative to the control was determined. The increase of chlorophyll a was greater than of chlorophyll b.

Five spring wheat cultivars (Banti, Łagwa, Parabola, Sewilla and Żura) were subjected to pre-sowing treatment with alternating magnetic field. Two exposure doses were applied: $\mathrm{D} 1=21.50 \mathrm{~kJ} \mathrm{~m}^{-3} \mathrm{~s}(30 \mathrm{mT}, 30 \mathrm{~s})$ and $\mathrm{D} 2$ $-7.16 \mathrm{~kJ} \mathrm{~m}^{-3} \mathrm{~s}(30 \mathrm{mT}, 10 \mathrm{~s})$ (Pietruszewski et al., 2013). Germination kinetics was measured by means of the electronic seed germinator (Patent, PL 378397) every $1 \mathrm{~h}$. Then the kinetics was described by means of a logistic curve and its parameters were determined. The experimental data permitted the conclusion that each of the wheat cultivars responded individually to the magnetic field applied.

The cited studies on the effect of alternating magnetic field on plant seeds are compiled in Table 5.

\section{CONCLUSIONS}

The effect of magnetic field on plant seeds has been researched over a very broad range of values of magnetic induction. The values varied from just over ten microteslas to as much as $10 \mathrm{~T}$. The difference between those extreme values is of the order of one million times. The effect of magnetic field depends on its energy $i e$ on the value of magnetic induction squared. Hence, comparing the extreme cases, the effects of those fields differed $10^{12}$-fold. And the scale of those differences makes the comparison of the effects of those fields difficult.

Alternating magnetic induction of $15 \mu \mathrm{T}$ and $50 \mathrm{~Hz}$ was applied in the determination of its effect on the germination of seeds of cork oak (Celestino et al., 1998). Magnetic fields in the range of $40-78 \mu \mathrm{T}$ and $60 \mathrm{~Hz}$ were applied to determine their effect on the germination of seeds of several plant species (Davis, 1996).

Another type of research is presented in a paper by Hirota et al. (1999) who applied a static magnetic field of very high magnetic induction, in this case $10 \mathrm{~T}$. Such a strong magnetic field was obtained through the use of the phenomenon of superconductivity. In fields of 10 and $7 \mathrm{~T}$ greatly improved germination of cucumber seeds was observed relative to the germination in the control sample. 
This is clearly seen in the several publications released in recent years. A detailed review quotes 267 different articles, in which the range of the magnetic fields applied is very large (Gallant and Pazur, 2005). This can be seen also in a collective work (Hunt et al., 2009), in which 201 scientific articles were analysed and quoted. The recent publications comprise 2 articles (Dhawi, 2014; Maffei, 2014). Within these works the authors quote a number of publications where the range of magnetic induction applied varies from $\mathrm{mT}$ to $\mathrm{T}$, thus differs up to the level of 109 times.

Comparing those studies one can note that in spite of very large differences in the values of magnetic induction applied the effects are highly similar - a positive effect of alternating magnetic field is observed.

A separate issue is the application of static and alternating magnetic fields. At present the mechanism of magnetic field effect on seeds and plants is not known, but one can say that the mechanism will be different in the case of static magnetic field and different in the case of alternating magnetic field. In most of the references cited a positive effect is observed for lower values of magnetic induction of an alternating field than in the case of a static magnetic field.

The cited research results cannot provide an unambiguous explanation of the mechanism of magnetic field effect on living organisms, in this case plant seeds. However, we can suppose that alternating magnetic field stimulates enzymatic activity, which causes an increase in seed germination speed. Stimulated seeds not only germinate faster, but also more uniformly, they start vegetation as plants earlier, and thanks to this higher yields are obtained. At this point we can refer to the remarks of Wadas (1991) who states that magnetic field, below a certain limit value of intensity which is hard to define for various organisms, causes an increase of enzyme activity, accelerating their metabolism. Increased enzyme activity under the effect of magnetic fields is observed also in the organisms of animals. It is assumed, therefore, that this can be considered as a general rule of nature. It should also be emphasised that in the effect of magnetic field on living organisms there is an absence of any selectivity of that field. Magnetic field acts on all molecules, and thus also on those that do not require its effect.

Weiss and Zerrenthin(1987)noted that although the effect of magnetic fields on living organisms (humans, animals, plants) fascinated researchers for a long time, magnetobiophysics as a science is still at its beginnings. He believes that in the nearest future magnetic fields will be applied on a large scale in biology, medicine, agriculture and in the economics of food materials.

The occurrence of excited states of ions and magnetic molecules is the exclusive feature of living organisms. Such states are caused by the effect of electrostatic, magnetostatic, electromagnetic and gravitational fields. The mutual relations among those fields, their astonishing synthesis in living organisms, and the relation of those fields with life are problems facing physicists and biologists (Wadas, 1991).

The Malthus-Verhulst logistic equation proved to be highly useful for the estimation of the effect of magnetic field. That equation was also successfully applied by Mahajan and Pandey (2011) for the determination of the effect of magnetic field on the germination of black gram seeds. The comparison of the parameters of the logistic curve and the germination kinetics curves permits correct determination of the effect of magnetic field on plant vegetation. That effect is strongly varied. It depends on the exposure dose $i e$ the intensity of magnetic field and the time of exposure, but also it depends on the plant species and cultivar. The data presented herein demonstrate clearly that there is no possibility of an unambiguous statement that magnetic field effects are positive or negative. Studies on germination kinetics are laboratory studies. They provide information, but the information is of a preliminary character and should be verified based on field experiments.

\section{REFERENCES}

Ablu El-Yozied, El-Gizawy A.M., Khalf S.M., El-Satar A., and Shalaby O.A., 2012. Effect of magnetic field treatment and irrigation water as well as N, P, and K levels on productivity of tomato plants. J. Appl. Sci. Res., 8(4), 2088-2099.

Aguilar C.H., Dominguez-Pacheco A., Carballo Carballo A., Cruz-Orea A., Ivanom R., Lopez Bonilla J.l., and Valcarcel Montoñez J.P., 2009. Alternating magnetic field irradiation on three genotype maize seed. Acta Agrophysica, 14(1), 7-17.

Aksenov S.I., Gruzina T.I., and Gorichev S.N., 2001. Characteristic of low frequency magnetic field effect on swelling of wheat seeds at various stages. Biofizika, 46, 1127-1132.

Aladjadjiyan A., 2007. The use of physical method for plant growing stimulation in Bulgaria. J. Centre European Agric., 8(3), 369-380.

Aladjadjiyan A., 2010. Influence of stationary magnetic field on lentil seeds. Int. Agrophys., 24, 321-324.

Aleman E.I., Moreira R.O., Lima A.A., Silva S.Ch., GonzalezOlmedo J.L., and Chalfun-Junior A., 2014. Effect of 60 $\mathrm{Hz}$ sinusoidal magnetic field on in vitro establishment multiplication and acclimatization phases of coffee Arabica seedling. Bioelectromagnetics, 35, 414-425.

Atak C., Emiroğlu Ö., Alikamenğlu S., and Razkoulieva A., 2003. Stimulation of regeneration by magnetic field in soybean (Glicine $\max$ L. Merrill) tissue cultures. J. Cell Molecular Biol., 2, 113-119.

Audus L.J., 1960. Magnetotropism: A new plant growth response. Nature, 185, 132-134.

Balonchi H.R. and Moderres Sanavy S.A.M., 2009. Electromagnetic field impact on annual medick and dodder seed germination. Int. Agrophys., 23, 111-115.

Barnothy M.F. (Ed.), 1964. Biological Effect on Magnetic Fields. Plenum Press, New York, USA.

Barnothy M.F. (Ed.), 1969. Biological Effect on Magnetic Fields. Plenum Press, New York-London. 
Bujak K. and Frant M., 2009. Effect of pre-sowing stimulation with alternating magnetic field on yields of spring wheat (in Polish). Acta Agrophysica, 14(1), 19-29.

Carbonell M.V., Martinez E., and Amaya J.M., 2000. Stimulation of germination in rise (Oryza savita L.) by a static magnetic field. Electro- and Magnetobiol., 19, 121-128.

Celestino C., Picazo M.L., Torbio M., Alvarez-Ude J.A., and Bardasano J.L., 1998. Influence of $50 \mathrm{~Hz}$ electromagnetic fields on recurrent embryogenesis and germination of cork somatic embryos. Plant Cell, Tissue Organ Culture, 54, 65-69.

Chao L. and Walker D.R., 1967. Effect of magnetic field on germination on apple, apricot and peach seed. Hort. Sci., 2, 152-153.

Cholodov J.A. (Ed.), 1978. Reaction of Biological Systems on Magnetic Field (in Russian). Nauka, Moskwa, Russia.

Danilewski W.J., 1971. Studies on the influence of electricity on physiology of plants (in Polish). In: Electromagnetic fields and living nature (Ed. A.S. Presman). PWN, Warsaw, Poland.

Davis M.S., 1996. Effect of $60 \mathrm{~Hz}$ electromagnetic field on early growth in three plant species and a replication of previous results. Bioelectromagnetics, 17, 154-161.

D'Astre A.S., 1882. Influence physiologique de l'etat magnitique, In: Biological Effect on Magnetic Fields (Ed. M.F. Barnothy). Plenum Press, Paris, France.

Dhawi F., 2014. Why magnetic field are used to enhance a plant's growth productivity? Ann. Res. And Rev. Biology, 4(6), 886-896

Dziwulska-Hunek A., Kornarzyński K., Matwijczuk A., Pietruszewski S., and Szot B., 2009. Effect of laser and variable magnetic field stimulation on amaranth seeds germination. Int. Agrophys., 23, 215-227.

Dziwulska-Hunek A. and Kornarzyński K., 2009. Germination of amaranth seeds cv. Aztek and Rawa at various temperatures (in Polish). Acta Sci. Pol., Technica Agraria, 8(1-2), 3-10.

Eward A., 1903. On the physics and physiology of protoplasmatic streaming in plants. In: Electromagnetic Fields and Living Nature (in Polish) Presman A.S., 1971, PWN, Warsaw, Poland.

Fiszer G., Tausz M., and Gill D., 2004. Effect of weak $16^{2} / 3 \mathrm{~Hz}$ magnetic field on growth parameters of young sunflower and wheat seedling. Bioelectromagnetics, 25, 638-641.

Flórez M., Martinez E., and Carbonell M.V., 2012. Effect of magnetic field treatment on germination of medicinal plant. Pol. J. Environ. Stud., 21, 1 57-63.

Hirota N.M., Nakagawa J., and Kitazawa K., 1999. Effect of magnetic field on the germination of plant. J. Appl. Physics, 85(8), 5717-5719.

Galland P. and Pazur A., 2005. Magnetoreception in plants. J. Plant Res., 118, 371-389.

Guttzeit H.O., 2001. Biological effect of ELF-EMF enhanced stress response; new insights and new questions. Electro Magnetobiology, 20, 15-26.

Hunt R.W., Zavalin A., Bhatnagar A., Chinnasamy S., and Das K.C., 2009. Electromagnetic biostimulation of living cultures for biotechnology, biofuel and bioenergy application. Int. J. Molecular Sci., 10, 4515-4558.
Iqbal M., Haq Z.U., Jamil Y., and Achmed M.R., 2012. Effect of pre-sowing magnetic treatment on properties of pea. Int. Agrophys., 26, 25-31.

Kania K., Pietruszewski S., and Kornarzyński K., 2007. Apparatus for determination of seeds germination capacity. Patent, PL 378397.

Kopeć B., 1984. Effect of electric and magnetic fields on biological properties of seeds (in Polish). Ph.D. Thesis, WTR AR Lublin, Poland

Kopeć B., 1985. Application of magnetic field for pre-sowing treatment of seeds (in Polish). Post. Nauk Roln., 1, 93-100.

Kornarzyński K. and Pietruszewski S., 2005. Influence of large doses of alternating magnetic field on germination of durum wheat seeds (in Polish). Acta Sci. Pol., Technica Agraria, 4(2), 11-20.

Maffei M.E., 2014. Magnetic field effect on plant, growth, development, and evolution. Front. Plant Sci., 5, 445-462.

Mahajan T.S. and Pandey O.P., 2011. Reformulation of Malthus-Verhulst equation for black gram seeds pretreated with magnetic field. Int. Agrophys., 25, 355-359.

Mahajan T.S. and Pandey O.P., 2014. Magnetic-time model at off-season germination. Int. Agrophys., 28, 57-62

Marks N. and Szecówka P.S., 2010. Impact of variable magnetic field stimulation on growth of aboveground parts of potato plants. Int. Agrophys., 24, 165-170.

Martinez E., Carbonell M.V., and Amaya J.M., 2000. A static magnetic field of $125 \mathrm{mT}$ stimulates in initial growth stages of barley (Hordeum vulgare L.). Electro- and Magnetobiol., 19, 271-277.

Martinez E., Carbonell M.V., Flórez H., Amaya J.M., and Maqueda R., 2009. Germination of tomato seeds (Lycopersicon esculantum L.) under magnetic fields. Int. Agrophysics, 23, 44-50.

Matwijczuk A., Kornarzyński K., and Pietruszewski S., 2012. Effect of magnetic field on germination and seedling growth of sunflower. Int. Agrophys., 26, 271-278.

Moreón L.P., Castro Palacio J.C., Velázquez Abad L., and Govea A.P., 2007. Stimulation of Pinus Tropicalis M. seeds by magnetically treated water. Int. Agrophysics, 21, 173-177,

Muszyński S., Gagoś M., and Pietruszewski S., 2009. Shortterm pre-germination exposure to ELF magnetic field does not influence seedling growth in durum wheat (Triticum durum). Polish J. Environ. Study, 18(6), 1065-1072.

Novitsky Y.I., Novitskaya G.V., Kosheshova T.K., Nechiporenko G.A., and Dobrovol'skij M.V., 2001. Growth of green onions in a weak permanent magnetic field. J. Plant Physiol., 48, 709-715.

Novitskii Y.I., Novitskaya G.V., and Serdyukov Y.A., 2014. Lipid utilization in radish seedlings as affected by weak horizontal extremely low frequency magnetic field. Bioelectromagnetics, 35, 91-99.

Pietruszewski S., 1999. Magnetic biostimulation of spring wheat sowing material (in Polish). Rozprawy Naukowe AR Lublin, Poland.

Pietruszewski S. and Wójcik S., 2000. Effect of magnetic field on field and chemical composition of sugar beet. Int. Agrophysics, 14, 89-92.

Pietruszewski S., 2001. Modeling by logistic curie germination of wheat seeds Henika cultivar in magnetic field (in Polish). Acta Agrophysica, 58, 143-151. 
Pietruszewski S., Kornarzyński K., and Lacek R., 2001 . Germination of wheat seeds grain in an alternating magnetic field. Int. Agrophysics, 15, 269-271.

Pietruszewski S., Kornarzyński K., and Lacek R., 2001 b. Germination of wheat seeds in static magnetic field (in Polish). Inż. Roln., 303-307.

Pietruszewski S., 2002. Influence of magnetic fields on seeds germination of selected cultivated plants (in Polish). Acta Sci. Pol., Technica Agraria, 1(1), 75-81.

Pietruszewski S. and Kania K., 2010. Effect of magnetic field on germination and yield of wheat. Int. Agrophys., 24, 275-302.

Pietruszewski S., Muszyński S., and Dziewulska A., 2007. Electromagnetic fields and electromagnetic radiation as non-invasive external stimulants for seeds (selected methods and responses). Int. Agrophysics, 21, 95-100.

Pietruszewski S., Szecówka P.S., and Kania K., 2013. Effect of pre-sowing magnetic stimulation on germination of kernels of various spring wheat varieties (in Polish). Acta Agrophysica, 20(2), 415-425.

Pitman U.J., 1963. Magnetism and plant growth: I Effect of germination and early growth of cereals seeds. Can. J. Plant Sci., 43, 513-518.

Pitman U.J., 1965. Magnetism and plant growth: III Effect of germination and early growth of corn and beans. Can. J. Plant Sci., 45, 549-555.

Pitman U.J., 1967. Biomagnetic responses in Kharkov $22 \mathrm{MC}$ Winter Wheat. Can. J. Plant Sci., 47, 389-393.

Pitman U.J., Carefood J.M., and Ormrod D.P., 1979. Effect of magnetic seed treatment on amylolytic activity of quiescent and germinating barley and wheat. Can. J. Plant Sci., 59, 1007-1011.

Pitman U.J. and Ormrod D.P., 1970. Physiological and Chemical features of magnetically treated winter wheat seed and resultant seedling. Can. J. Plant Sci., 50, 211-217.

Pitman U.J. and Ormrod D.P., 1971. Biomagnetic responses in germinating barley. Can. J. Plant Sci., 51, 64-65.

Podleśny J., Pietruszewski S., and Podleśna A., 2004. Efficiency of magnetic biostimulation of broad bean cultivated in experimental plot conditions. Int. Agrophysics, 18, 65-71.

Podleśny J., Misiak L.E., Podleśna A., and Pietruszewski S., 2005. Concentration of free radicals in pea seeds after presowing treatment with magnetic field. Int. Agrophysics, 19, 243-249.

Presman A.S., 1971. Electromagnetic Fields and Living Nature (in Polish). PWN, Warsaw, Poland.

Ratushnyak A.A., Andreeva M.G., Morozova G.A., and Trushin M.V., 2008. Effect of extremely high frequency electromagnetic fields on microbiological community in rhizosphere of plants. Int. Agrophysics, 22, 71-74.

Reinke J., 1876. Untersuchungen der Wachstrum. Botan. Ztg. 34, 129. In: Biological Effect on Magnetic Fields (Ed. M.F. Barnothy). Plenum Press, 1, 183-195.
Rochalska M. and Grabowska K., 2007. Influence of magnetic field on activity of enzyme $\alpha$ - and $\beta$ - amylase and glutathione s-transfere (GST) in wheat plants. Int. Agrophysics, 21, 185-188.

Rochalska M., Grabowska-Topczewska K., and Mackiewicz A., 2011. Influence of alternating low frequency magnetic field on improvement of seed quality. Int. Agrophys., 25, 265-269.

Sawostin P.W., 1930. Magnetic growth reaction in plants. Planta, 12, 327-333.

Shashurin M.M., Prokopiev A.A., Shein G.V., Filippova G.V., and Zhuravskaya A.N., 2014. Physiological responses of Plantago media to electromagnetic field of power-line frequency (50 Hz). Russian J. Plant Physiol., 61, 4, 484-488.

Simi T., Anjali A., Viswantham Ch., Anil D., and Sudipta B., 2013. Magnetopriming circumvents the effect of salinity stress in germination in chichpea. Acta Physiol. Plant., 35, 3401-341.

Sujak A., Dziwulska-Hunek A., and Kornarzyński K., 2009. Compositional and nutritional values of amaranth seeds after pre-sowing He-Ne laser light and alternating magnetic field treatment . Int. Agrophys., 23, 81-89.

Sujak A. and Dziwulska-Hunek A., 2010. Minerals and fatty acids of amaranth seeds subjected to pre-sowing electromagnetic stimulation. Int. Agrophys., 24, 375-379.

Tolomei G., 1893. Anzione del magnetismo sulla germinazione. Malpighia, 7, 470. In: Biological Effect on Magnetic Fields (Ed. M.F. Barnothy). Plenum Press, 1, 183-195.

Torres M. and Frutos G., 1990. Logistic function analysis of germination behaviour of aged fennel seeds. Environ. Exp. Botany, 30, 3, 383-390.

Vashisth A. and Nagarajan S., 2008. Exposure of seeds to static magnetic field enhances germination and early growth characteristics in chickpea (Cicer arientinum L.). Bioelectromagnetics, 29, 571-578.

Vashisth A. and Nagarajan S., 2010. Effect of germination growth characteristics in sunflower (Helianthus annuus L.) seeds exposed to static magnetic field. J. Plant Physiol., 167, 149-156.

Wadas R., 1991. Biomagnetism. PWN, Warszawa.

Weiss H. und Zerrenthin U., 1987. Die magnetische Suszeptolbilotöt - eine physilalische Grösse zur Saatguberteilung. Seed Sci. Technol., 15, 247-254.

Zepeda-Bautista R., Hernandez-Aguilar C., DominguezPachecco A.F., Cruz-Orea A., Godina-Nova J.J., and Martinez-Ortiz E., 2010. Electromagnetic field and seed vigour of corn hybrids. Int. Agrophys., 24, 329-332.

Zepeda-Bautista R., Hernandez-Aguilar C., Suazo-Lopez F., Dominguez-Pachecco A.F., Virgen-Varas J., PerezReyes C., and Peon-Escalante I., 2014. Electromagnetic field in corn grain production and health. African $\mathrm{J}$. Biotechnol., 13(1), 76-83. 